\title{
Surveillance in surgery prevents infections and ensures good quality
} of care

\author{
Diana Vilar-Compte*1, Samuel Rosales Pérez ${ }^{1}$, Inés Álvarez de Iturbe ${ }^{1}$, \\ Eduardo Maafs², Carlos Robles-Vidal², Enrique Bargallo², Ma Cruz Pérez- \\ Amador $^{3}$ and Patricia Volkow ${ }^{1}$
}

\author{
Address: ${ }^{1}$ Department of Infectious Diseases, Instituto Nacional de Cancerologia (INCan), México, ${ }^{2}$ Breast Tumor Department, INCan, México \\ and ${ }^{3}$ Department of Anesthesia, INCan, México \\ Email: Diana Vilar-Compte* - parakalomx@yahoo.com.mx \\ * Corresponding author
}

from 24th Annual Meeting of the National Cancer Institute of Mexico

Mexico City, Mexico. 14-17 February 2007

Published: 5 February 2007

BMC Cancer 2007, 7(SuppI I):A3 doi:10.1 186/I47|-2407-7-SI-A3

This article is available from: http://www.biomedcentral.com/I47I-2407/7/SI/A3

(c) 2007 Vilar-Compte et al; licensee BioMed Central Ltd.

\section{Background}

Surveillance is cost-effective in surgery. It's shown to decrease surgical site infections (SSI's) and other surgery related complications. SSI rate is considered a quality care index. The objective of this study was to describe a 5-year experience with a continuous, prospective surveillance program in patients undergoing mastectomy.

\section{Methods}

Since 2000, when poor compliance to infection control policies and high rates of infection (SSI:33.1\%) were detected at the Breast Tumor Department, surveillance has been conducted by direct observation along with surgeons. Preventive policies were introduced in 2001 (strict prophylactic antibiotics, closed suction drains and feedback to surgeons). In 2004 we studied perioperative hyperglycemia as a risk factor for SSI in selected patients. We constructed control charts for SSI analysis. Univariate and stratified analysis were performed.

\section{Results}

2340 surgeries were monitored. After the introduction of preventive policies, SSI's dropped 50\%. In 2001 and 2002 SSI remained within acceptable limits, but in 2003 we observed 2 peaks of SSI above control limits. These peaks were linked to poor quality drainages $(\mathrm{OR}=1.96,95 \% \mathrm{CI}$ $=1.2-3.3, \mathrm{p}=0.004)$ and low performance of surgical residents. At the end of 2004 another peak of SSI was observed when $\mathrm{J}-\mathrm{Vac}^{\circledast}$ was introduced without personal training. Antibiotic prophylaxis was prescribed in accordance to guidelines in 2001 (95\%) patients, and 62\% was timeliness. In patients in which perioperative glucose was determined $(\mathrm{n}=260)$, we observed that any glucose $>=150 \mathrm{mg} / \mathrm{dL}$, increased the risk of SSI (OR $=3.0595 \% \mathrm{CI}$ $=1.5-6.3, p=0.006$ ).

\section{Conclusion}

Preventive policies were effective in reducing SSI. Continuous and prospective surveillance detected an increase on complications related to poor quality and inappropriate drainages. Perioperative glucose values $>150 \mathrm{mg} / \mathrm{dL}$ seems to be associated with an increased risk of SSI in patients undergoing mastectomy. Surveillance is mandatory to ensure appropriate quality standards. 